\title{
Back pain in physically inactive students compared to physical education students with a high and average level of physical activity studying in Poland
}

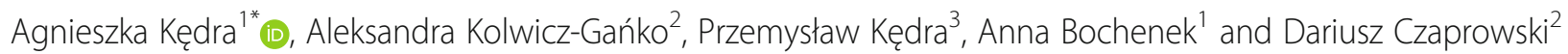

\begin{abstract}
Background: The aim of the study was (1) to characterise back pain in physically inactive students as well as in trained (with a high level of physical activity) and untrained (with an average level of physical activity) physical education (PE) students and (2) to find out whether there exist differences regarding the declared incidence of back pain (within the last 12 months) between physically inactive students and PE students as well as between trained (with a high level of physical activity) and untrained (with an average level of physical activity) PE students.

Methods: The study included 1321 1st-, 2nd- and 3rd-year students (full-time bachelor degree course) of Physical Education, Physiotherapy, Pedagogy as well as Tourism and Recreation from 4 universities in Poland. A questionnaire prepared by the authors was applied as a research tool. The 10-point Visual Analogue Scale (VAS) was used to assess pain intensity. Prior to the study, the reliability of the questionnaire was assessed by conducting it on the group of 20 participants twice with a shorter interval. No significant differences between the results obtained in the two surveys were revealed $(p<0.05)$.

Results: In the group of 1311 study participants, 927 (70.7\%) respondents declared having experienced back pain within the last 12 months. Physically inactive students declared back pain frequency similar to the frequency declared by their counterparts studying physical education $(p>0.05)$. Back pain was more common in the group of trained students than among untrained individuals $(p<0.05)$. Back pain was mainly located in the lumbar spine.

Conclusions: A frequent occurrence of back pain (70.7\%) was noted in the examined groups of students. The percentage of students declaring back pain increased in the course of studies $(p<0.05)$ and, according to the students' declarations, it was located mainly in the lumbar spine. No significant differences regarding the incidence of back pain were found between physically inactive students and physical education students $(p>0.05)$. The trained students declared back pain more often than their untrained counterparts $(p<0.05)$.
\end{abstract}

Keywords: Pain, Spine, Students, Trained individuals, Physical activity

\footnotetext{
*Correspondence: agnieszka.kedra@poczta.fm

'Jozef Pilsudski University of Physical Education in Warsaw, Faculty of

Physical Education and Sport, ul. Akademicka 2, 21-500 Biala Podlaska, Poland

Full list of author information is available at the end of the article
} 


\section{Background}

Back pain is a common health issue that constitutes the main reason for sick leaves and disability retirement of working individuals, which, in turn, generates considerable costs in the healthcare system [1-3]. The results of the studies from the last 25 years indicate that back pain is declared not only by adults and elderly individuals but also by adolescents and even school children [4-6]. Risk factors predisposing young people to back pain mainly include low body height [7], female gender [4, 5, 8-10], mental disorders [11], and depression and stress [4]. Modifiable risk factors include smoking tobacco [4], time spent in front of the TV [5], and high or low levels of physical activity $[12,13]$. Studies revealed that physical activity is significant for preventing and treating back pain [14-18]. However, both passivity and excessive physical activity may increase the risk of back pain [12]. Numerous studies carried out on groups of young individuals doing sports revealed that back pain is a common phenomenon [19-22]. To date, back pain in athletes has been analysed in comparison to the group of physically inactive individuals; however, correlations between back pain and physical activity at different levels have not been verified. Therefore, it is significant to complete the current body of knowledge with such an analysis.

Physical education students constitute a specific group of individuals with a moderate and high level of physical activity. They take up physical activity within their obligatory physical education classes which are included in the study curriculum. Moreover, a considerable group of students of physical education are athletes who have been training various individual and team sports for many years.

The aim of the study was (1) to characterise back pain in physically inactive students as well as trained and untrained PE students and (2) to find out whether there exist differences regarding the declared incidence of back pain (within the last 12 months) between physically inactive students and PE students as well as between trained and untrained PE students.

\section{Methods}

\section{Study participants}

The study included 1321 1st-, 2nd- and 3rd-year students (full-time bachelor degree course) of Physical Education, Physiotherapy, Pedagogy as well as Tourism and Recreation from 4 universities in Poland. The sample was randomly selected with the use of multistage cluster design [23]. The first stage included a random selection of universities from particular regions of eastern Poland that educate students in various fields, one of them necessarily being Physical Education. The second stage involved the selection of two fields of study at each university. At the final (third) stage, student groups (B.A. students) were selected from each field of study. The research included all the students who attended classes on the day of conducting the research (it was not repeated in the case of absent students). Students who gave their consent to participate in the research were qualified for it.

The final analysis included 1311 questionnaires constituting $99.2 \%$ of the study population. Taking into account the obtained questionnaires, the study participants were divided into two groups, i.e. (1) physically inactive students and (2) PE students. Moreover, the latter group was divided into two subgroups, i.e. (a) untrained PE students - an average level of physical activity and (b) trained PE students - a high level of physical activity. The inclusion criteria in the group of physically inactive students were as follows: taking one course only; being a student of the field of study other than physical education (or any other course connected with physical activity); studying at the 1st, 2nd or 3rd year of full-time bachelor degree course; attending no additional physical education classes apart from PE included in the curriculum; undergoing no sports training at the time of the research or in the past; taking up free time physical activity no more than once per week and no longer than $60 \mathrm{~min}$. The inclusion criteria in the group of untrained PE students - an average level of physical activity: taking one course only; studying at the 1st, 2nd or 3rd year of a PE course (Bachelor's degree); physical education classes constituting a minimum of $40 \%$ of the course curriculum (798 $\mathrm{h}$ in the period of 3 years); undergoing no training at the time of the research or in the past. In a 3year curriculum PE students attend the following obligatory sports classes: gymnastics, rhythmic gymnastics, dancing, swimming, athletics, handball, football, volleyball, basketball, motor games and plays, wrestling, fitness, weight training, winter camp (with such classes as alpine skiing and cross-country skiing), summer camp (with such classes as windsurfing, canoeing, field games and plays, survival, cycling), optional sports specialisation. Within three years of studying (six semesters) each student attends $798 \mathrm{~h}$ of sports classes. The inclusion criteria in the group of trained PE students - a high level of physical activity: taking one course only; studying at the 1st, 2nd or 3rd year of a PE course (Bachelor's degree); physical education classes constituting a minimum of $40 \%$ of the course curriculum (798 $\mathrm{h}$ in the period of 3 years); training a minimum of 60 min per day - 5 times per week, training experience - a minimum of 3 years, break from training within the last year no longer than 1 week. The group of trained students included individuals who trained one of the following team sports: handball, football, volleyball or basketball.

Individuals taking more than one course were excluded from the study, since four PE students additionally studied a course which had no physical activity in the curriculum (pedagogics, geography) and including these individuals in the analysis might mean that the same student could be counted in two different groups. Moreover, one student 
experiencing pain only during pregnancy and two students feeling pain only during menstruation were excluded from the study, since there is evidence that these ailments experienced by women in these periods may result, inter alia, from endocrine disruptions and it is difficult to qualify them unequivocally as back pain [24].

\section{Diagnostic tool}

A questionnaire prepared by the authors was applied as a research tool. All the students filled in the questionnaire during classes at the university (practical classes or lectures) with one of the study authors present. The first page of the questionnaire included an explanation of the study aim and instructions. The questionnaire consisted of multiple choice questions allowing respondents to select only one answer (14 questions) or multiple answers (2 questions). Moreover, 9 multiple choice questions included a comment section. Personal information section consisted of questions about university course or courses, age, year of studying, gender, body mass and height, training (sport, number of training days per week, number of training hours per day).

The main section of the questionnaire included questions regarding:

a) experiencing back pain within the last year (12 months). Individuals who responded negatively to this question, were asked not to answer the remaining questions;

b) pain frequency, location and intensity;

c) types of situations in which back pain occurred or increased (Additional file 1).

In order to assess the intensity of pain, Visual Analogue Scale (VAS) was applied. The subject's task was to mark their maximal pain level from the previous month on a 10-cm line. Then, the centimetres marked by the respondents were measured and converted into point scale and classified according to the following key: 0 - no pain, 1-3 - mild pain, 4-6 - moderate pain, 7-10 - severe pain [25].

Prior to the study, the reliability of the questionnaire was assessed by conducting the survey twice in the group of 20 participants (5 persons from each of the four courses) with a 1-month interval. Kappa coefficient in all the variables was equal to or higher than 0.93. No significant differences between the results obtained in both tests $(p<0.05)$ were found.

The questionnaire was anonymous and voluntary. The study was accepted by the Ethical Commission of Scientific Research of Jozef Pilsudski University of Physical Education in Warsaw, Poland.

\section{Statistical methods}

The analysis was made with the use of descriptive statistics. A non-parametric Chi-square test was applied. The odds ratio (OR) and corresponding 95\% confidence interval was calculated. Calculations were made with the use of SPSS 9.0 software and Excel spread sheet. The level of significance was set at alfa $<0.05$.

\section{Results}

\section{Declared back pain occurrence}

In the group of 1311 study participants, 927 (70.7\%) respondents declared having experienced back pain within the last 12 months. Taking into account the nature of the course, it may be concluded that physically inactive students declared back pain at a frequency similar to that declared by their counterparts studying PE (70.4 and $71.2 \%$, respectively), $p>0.05$ (OR CI $1.095 \% 0.82$ 1.32). Back pain is more common among the trained students than their untrained peers $(75.3$ and $67.8 \%$, respectively) and this is a statistically significant difference at the level of $p<0.05$. It is also confirmed by the value of the odds ratio, i.e. 1.5 (95\% CI 0.99-2.1) (Table 1). In all the examined groups of students, the declared occurrence of back pain increased in the course of studies ( $\mathrm{p}$ $<0.05$ ) (Table 1).

\section{Declared back pain incidence}

Having analysed the declared incidence of back pain, it may be concluded that the biggest group is constituted by respondents who experienced pain rarely, i.e. 1-2 times per year (53.4\%). While analysing the frequency of back pain with regard to the type of studies, it was noted that physically inactive students and PE students declared a similar frequency of back pain, i.e. very rare pain (1-2 times per year) -54.8 and $51.6 \%$, respectively, and pain occurring a few times per year (3-6 times/year) - 34.6 and $31.0 \%$, respectively. Frequent and constant pain (more than 1-2 times per month) was declared more often by PE students than by physically inactive students (10.6 and $17.4 \%$, respectively) $(p<0.05)$. Pain occurring 1-2 times per year was more common among untrained students than among their trained counterparts, while frequent or constant pain was declared more often by trained students than by untrained ones. However, the difference was not statistically significant $(p>$ 0.05) (Table 2).

\section{Back pain location}

The question concerning pain location was a multiple choice question allowing more than one answer. Back pain was mainly located in the lumbar spine. This location was declared by $87.4 \%$ of the respondents. The analysis of pain location with regard to the type of studies revealed that physically inactive students declared pain in the cervical and lumbar spine more often than PE students $(p<0.05)$ (Table 2). 
Table 1 Incidence of BP with regard to the year of studies depending on the active or inactive character of studies $(n=1311)$

\begin{tabular}{|c|c|c|c|c|c|c|c|c|c|c|c|c|}
\hline & \multirow{2}{*}{\multicolumn{2}{|c|}{$\frac{\text { Students }}{\mathrm{T}(\mathrm{PIS} / \mathrm{PES})}$}} & \multirow{2}{*}{\multicolumn{2}{|c|}{$\frac{\text { Students }}{\text { PIS }}$}} & \multirow[b]{3}{*}{$p$ value } & & & \multicolumn{5}{|c|}{ PE students } \\
\hline & & & & & & \multicolumn{2}{|c|}{ TPES (UT/T) } & \multicolumn{2}{|l|}{$\overline{U T}$} & \multirow[b]{2}{*}{$p$ value } & \multicolumn{2}{|l|}{$T$} \\
\hline & $\mathrm{n}$ & $\%$ & $\mathrm{n}$ & $\%$ & & $n$ & $\%$ & $n$ & $\%$ & & $n$ & $\%$ \\
\hline \multicolumn{13}{|l|}{ BP incidence } \\
\hline TOTAL & \multicolumn{2}{|c|}{$(n=1311)$} & \multicolumn{2}{|c|}{$(n=739)$} & & \multicolumn{2}{|c|}{$(n=572)$} & \multicolumn{2}{|c|}{$(n=317)$} & & \multicolumn{2}{|c|}{$(n=255)$} \\
\hline No & 384 & 29.3 & 219 & 29.6 & (NS) & 165 & 28.8 & 102 & 32.2 & $<0.05$ & 63 & 24.7 \\
\hline Yes & 927 & 70.7 & 520 & 70.4 & & 407 & 71.2 & 215 & 67.8 & & 192 & 75.3 \\
\hline \multicolumn{13}{|c|}{$\begin{array}{l}\mathrm{BP} \text { incidence } \\
\text { With regard to the year of studies }\end{array}$} \\
\hline 1st-year students & \multicolumn{2}{|c|}{$(n=462)$} & \multicolumn{2}{|c|}{$(n=278)$} & & \multicolumn{2}{|c|}{$(n=184)$} & \multicolumn{2}{|c|}{$(n=105)$} & & \multicolumn{2}{|c|}{$(n=79)$} \\
\hline No & 186 & 40.3 & 112 & 40.3 & (NS) & 74 & 40.2 & 46 & 43.8 & (NS) & 28 & 35.4 \\
\hline Yes & 276 & 59.7 & 166 & 59.7 & & 110 & 59.8 & 59 & 56.2 & & 51 & 64.6 \\
\hline 2nd-year students & \multicolumn{2}{|c|}{$(n=510)$} & \multicolumn{2}{|c|}{$(n=294)$} & & \multicolumn{2}{|c|}{$(n=216)$} & \multicolumn{2}{|c|}{$(n=115)$} & & \multicolumn{2}{|c|}{$(n=101)$} \\
\hline No & 163 & 32.0 & 84 & 28.6 & (NS) & 79 & 36.6 & 49 & 42.6 & $<0.05$ & 30 & 29.7 \\
\hline Yes & 347 & 68.0 & 210 & 71.4 & & 137 & 63.4 & 66 & 57.4 & & 71 & 70.3 \\
\hline 3rd-year students & \multicolumn{2}{|c|}{$(n=339)$} & \multicolumn{2}{|c|}{$(n=167)$} & & \multicolumn{2}{|c|}{$(n=172)$} & \multicolumn{2}{|c|}{$(n=97)$} & & \multicolumn{2}{|c|}{$(n=75)$} \\
\hline No & 35 & 10.3 & 23 & 13.8 & $<0.05$ & 12 & 7.0 & 7 & 7.2 & (NS) & 5 & 6.7 \\
\hline Yes & 304 & 89.7 & 144 & 86.2 & & 160 & 93.0 & 90 & 92.8 & & 70 & 93.3 \\
\hline$p$ value & \multicolumn{2}{|c|}{$<0.05$} & \multicolumn{2}{|c|}{$<0.05$} & & \multicolumn{2}{|c|}{$<0.05$} & \multicolumn{2}{|c|}{$<0.05$} & & $<0.0$ & \\
\hline
\end{tabular}

$B P$ back pain, NS statistically insignificant, $P I S$ physically inactive students, $P E S$ physical education students, UT untrained PE students, $T$ trained PE students, $T$ total, TPES all PE students

\section{Back pain intensity}

The analysis of back pain intensity allowed us to conclude that moderate pain was the most common in the examined group as it was declared by $42.3 \%$ of the respondents. As for pain intensity with regard to the type of studies, physically inactive students declared mild and moderate pain (38.1 and 44.2\%, respectively) more often than PE students (34.2 and $39.8 \%$, respectively) ( $p<$ $0.05)$. Severe pain was more often declared by PE students than by physically inactive students (26.0 and $17.7 \%$, respectively). The analysis of back pain intensity in the group of PE students showed that untrained students declared mild pain more often than trained students (41.1 and 27.6\%, respectively), while severe pain occurred more often in trained students than among untrained ones (30.7 and 19.6\%, respectively) $(\mathrm{p}<0.05)$. Detailed data are presented in Table 2.

\section{Circumstances in which back pain occurred or increased}

The question concerning circumstances in which back pain occurred or increased was a multiple choice question allowing more than one answer. The most common circumstances in which back pain occurred or increased included sitting (49.3\%) and standing (36.1\%). While analysing the circumstances with regard to the type of studies, it was noted that in such circumstances as sitting (59.2\%), standing (39.0\%) and doing household chores (29.5\%) back pain occurred and increased in physically inactive students more often than in PE students $(p<$ 0.05). Physical effort caused or increased pain more often in PE students than in physically inactive students $(28.7$ and $21.5 \%$, respectively) $(\mathrm{p}<0.05)$. The study revealed no differences $(p>0.05)$ regarding circumstances in which back pain occurred or increased between the groups of untrained and trained students (Table 2).

\section{Discussion}

In the available literature of the subject we have found studies which analysed the occurrence of back pain among students; however, these are studies analysing only low back pain. We did not limit our study to low back pain but we took into account all segments of the spine. Moreover, in the analysis attention was paid to the specificity of physical education studies which allows for selecting individuals with various levels of physical activity (a high level of physical activity - trained students, average level of physical activity - untrained students).

Our research revealed that back pain (which occurred within the last 12 months) affected a considerable group (70.7\%) of students from Poland. Physically inactive students declared an incidence of back pain at a level similar to PE students ( 70.4 and $71.2 \%$, respectively), $p>0.05$. The similarity of the frequency of occurrence of back pain in physically inactive students and PE students may be related observations made by Heneweer et al. [12]. Their research conducted on 3664 randomly selected individuals over 
Table 2 Incidence, location, intensity and circumstances of BP in the group of students depending on the active or inactive character of studies $(n=927)$

\begin{tabular}{|c|c|c|c|c|c|c|c|c|c|c|c|c|}
\hline & \multirow{2}{*}{\multicolumn{2}{|c|}{$\begin{array}{l}\text { Students T } \\
\text { (PIS/PES) }\end{array}$}} & \multirow{2}{*}{\multicolumn{2}{|c|}{ Students PIS }} & \multirow[b]{4}{*}{$p$ value } & & & \multicolumn{5}{|c|}{ PE students } \\
\hline & & & & & & \multirow{2}{*}{\multicolumn{2}{|c|}{$\begin{array}{l}\text { TPES (UT/T) } \\
(n=407)\end{array}$}} & \multirow{2}{*}{\multicolumn{2}{|c|}{$\frac{\mathrm{UT}}{(n=215)}$}} & \multirow[b]{3}{*}{$p$ value } & \multirow{2}{*}{\multicolumn{2}{|c|}{$\frac{T}{(n=192)}$}} \\
\hline & \multicolumn{2}{|c|}{$(n=927)$} & \multicolumn{2}{|c|}{$(n=520)$} & & & & & & & & \\
\hline & $\mathrm{n}$ & $\%$ & $\mathrm{n}$ & $\%$ & & $\mathrm{n}$ & $\%$ & $\bar{N}$ & $\%$ & & $n$ & $\%$ \\
\hline \multicolumn{13}{|l|}{ BP incidence } \\
\hline Rare BP (1-2/year) & 495 & 53.4 & 285 & 54.8 & $<0.05$ & 210 & 51.6 & 120 & 55.8 & (NS) & 90 & 46.9 \\
\hline $\begin{array}{l}\text { BP several times per year } \\
\text { (3-6/year) }\end{array}$ & 306 & 33.0 & 180 & 34.6 & & 126 & 31.0 & 59 & 27.4 & & 67 & 34.9 \\
\hline $\begin{array}{l}\text { Frequent or constant BP } \\
\text { (more than } 1-2 \text { months) }\end{array}$ & 126 & 13.6 & 55 & 10.6 & & 71 & 17.4 & 36 & 16.7 & & 35 & 18.2 \\
\hline \multicolumn{13}{|l|}{ BP location (segment) ${ }^{a}$} \\
\hline Cervical & 176 & 19.0 & 128 & 24.6 & $<0.05$ & 48 & 11.8 & 30 & 14.4 & (NS) & 18 & 9.4 \\
\hline Thoracic & 167 & 18.0 & 100 & 19.2 & (NS) & 67 & 16.5 & 39 & 18.7 & (NS) & 28 & 14.6 \\
\hline Lumbar & 810 & 87.4 & 473 & 91.0 & $<0.05$ & 337 & 82.8 & 176 & 84.2 & (NS) & 161 & 83.9 \\
\hline \multicolumn{13}{|l|}{ BP intensity } \\
\hline Mild & 337 & 36.4 & 198 & 38.1 & $<0.05$ & 139 & 34.2 & 86 & 41.1 & $<0.05$ & 53 & 27.6 \\
\hline Moderate & 392 & 42.3 & 230 & 44.2 & & 162 & 39.8 & 82 & 39.2 & & 80 & 41.7 \\
\hline Severe & 198 & 21.4 & 92 & 17.7 & & 106 & 26.0 & 47 & 19.6 & & 59 & 30.7 \\
\hline \multicolumn{13}{|l|}{$\begin{array}{l}\text { Circumstances in which } \\
\text { BP occurs or increases }{ }^{a}\end{array}$} \\
\hline Sitting & 457 & 49.3 & 308 & 59.2 & $<0.05$ & 149 & 36.6 & 87 & 41.6 & (NS) & 62 & 32.3 \\
\hline Standing & 335 & 36.1 & 203 & 39.0 & $<0.05$ & 132 & 32.4 & 74 & 35.4 & (NS) & 58 & 30.2 \\
\hline Lying & 150 & 16.2 & 94 & 18.1 & (NS) & 56 & 13.8 & 31 & 14.8 & (NS) & 25 & 13.0 \\
\hline Lifting heavy objects & 246 & 26.5 & 143 & 27.5 & (NS) & 103 & 25.3 & 57 & 27.3 & (NS) & 46 & 24.0 \\
\hline $\begin{array}{l}\text { Performing everyday activities } \\
\text { (cleaning, cooking, getting dressed) }\end{array}$ & 222 & 23.9 & 143 & 27.5 & $<0.05$ & 79 & 19.4 & 42 & 20.1 & (NS) & 37 & 19.3 \\
\hline Physical effort & 229 & 24.7 & 112 & 21.5 & $<0.05$ & 117 & 28.7 & 56 & 26.8 & (NS) & 61 & 31.8 \\
\hline Don't remember & 81 & 8.7 & 38 & 7.3 & - & 43 & 10.6 & 25 & 12.0 & - & 18 & 9.4 \\
\hline Other & 51 & 5.5 & 34 & 6.5 & - & 17 & 4.2 & 8 & 3.8 & - & 9 & 4.7 \\
\hline
\end{tabular}

$B P$ back pain, NS statistically insignificant, PIS physically inactive students, PES physical education students, UT untrained PE students, $T$ trained PE students, $T$ total, TPES all PE students

at does not add up to $100 \%$ as the respondents were allowed to mark more than one answer $/ *$

25 years of age proved that the correlation between back pain and physical activity may be U-shaped. Both a sedentary lifestyle and high physical activity increased the risk of back pain [12].The authors drew attention to the fact that it is not the quantity of physical activity that is significant but its quality. A boundary between moderate physical activity and excessive activity also depends on physical fitness. It has to be highlighted that it is significant whether an individual is forced to take up physical activity or if it is voluntary [12]. On the other hand, the lack of differences between the examined groups regarding the declared frequency of occurrence of back pain definitely suggests that a deeper analysis of factors connected with the lifestyle of the respondents is necessary. Our research revealed that there are differences between the compared groups regarding circumstances in which back pain occurs.
In our research, declared pain was mainly located in the lumbar spine (87.4\%). The analysis of pain intensity showed that moderate pain occurred commonly. It can be noted that untrained students declared mild back pain more often than trained students (41.1 and 27.6\%, respectively), while severe pain occurred more often in trained students than in untrained ones (30.7 and 19.6\%) $p<0.05$. It may be assumed that a higher percentage of trained students declaring severe and strong pain might mean that the problem results from an improper training process (e.g. too big training loads, improper selection of exercises). Verification of such assumptions requires detailed analysis of training aspects; however, it is not the aim of this work.

The research by Lewandowski et al. (2011) on 461 Polish PE and physiotherapy students revealed an incidence 
of back pain (77 and 69\%, respectively) similar to our results. However, they analysed only low back pain and limited their analysis to 1st-year students only [26]. The research on 514 physically inactive Turkish students aged 17-29 years from the Faculty of Medicine, Engineering, Science-Literature, and Education revealed that back pain was experienced by $44.6 \%$ of the students from the Faculty of Medicine, 16.9\% from the Faculty of Engineering, 20.2\% from the Faculty of Education and 18.3\% from the Faculty of Science-Literature [27]. This Turkish study indicated a significantly lower incidence of back pain than in the case of Polish physically inactive students. It may result from the fact that the quoted study focused on the analysis of back pain risk factors and both sample selection criteria and inclusion criteria differed from our study. Similarly to the previous study, in this research only non-specific low back pain was analysed.

Our own research revealed that trained students experienced back pain more often than untrained students (75.3 and $67.8 \%$, respectively) $(p<0.05)$.

The incidence of back pain has been examined in several studies in the last few years [28-30]. The authors analysed thoraco-lumbar back pain in various sports (e.g. gymnastics $-67 \%$, water ski jumping $-45 \%$, football $-53 \%$, weightlifting $-71 \%$, wrestling $-77 \%$, hockey $-89 \%$, diving $-89 \%$ and tennis $-50 \%$ ) in which considerable spine loads may occur, and found a significant percentage of individuals declaring back pain [28-31]. It was also revealed that back pain occurred more often in sports and competitions which require substantial (especially axial) spinal loads as well as among untrained individuals [30-35].

The research on back pain in physically inactive students and PE students from Poland may contribute to the findings of research concerning this issue in other countries. The obtained results may serve as a stimulus for further research aimed at finding back pain risk factors.

\section{Study limitations and strengths}

A group of trained individuals included students who trained various team sports. Each of the sports has a specific type of training, which may have affected the occurrence and the location of back pain in athletes training particular sports. Another study limitation is that the study participants were not divided into gender groups for the analysis. It resulted from the fact that such a division would have brought about overrepresentation of women from the physically inactive group. It is related to the demographic structure of the group of PE students where females are in a minority. The fact that the study did not analyse freetime activities, number of hours spent in a sitting position, ways of sitting or other daily activities of the study participants which may have exerted either positive or negative influence on pain incidence is another study limitation.
Another drawback resulting from the methodology of a cross-sectional study is the lack of possibility to determine the cause and effect correlation between factors affecting pain and its effects. Only the fact that certain correlations exist was determined. Due to the fact that respondents were asked about detailed characteristics of their back pain within the last 12 months, the final analysis of the results should be carried out with certain caution. However, the questionnaire applied in our study is reliable and according to authors, it may be used in clinical practice.

A big sample group, random selection of students and study group uniformity are the study strengths. A high response rate was achieved (99.2\%). Information concerning physical activity and sport was gathered independently so as not to suggest further correlation. To the authors' knowledge, it is the first study which analyses the characteristics of back pain in students with regard to the character of studies (active or sedentary) and additionally takes into account the division into trained and untrained PE students.

\section{Perspectives}

In the examined group of trained students, a considerable percentage of participants declaring back pain was found. Further research should aim to analyse this group more broadly in terms of back pain characteristics and to find back pain risk factors. In the future, pain with regard to particular sports, training experience and the number of training days and hours should be analysed.

\section{Conclusions}

1. In the examined groups of physically inactive and PE students a very frequent occurrence of back pain (70.7\%) was noted. The percentage of students declaring back pain increased in the course of studies $(p<0.05)$ and according to the students' declarations, it was located mainly in the lumbar segment of the spine (87.4\%).

2. Physically inactive students most often declared mild and moderate pain. PE students declared severe and strong pain more often than physically inactive students $(\mathrm{p}<0.05)$.

3. No significant differences regarding the incidence of back pain were found between physically inactive students and PE students $(p>0.05)$. The trained students declared back pain more often than their untrained counterparts $(\mathrm{p}<0.05)$.

\section{Additional file}

Additional file 1: questionnaire in English - questions concerning the feeling and characteristics of back pain in the English language. (DOC $70 \mathrm{~kb})$ 


\section{Abbreviations}

PE: Physical education; VAS: Visual analogue scale

\section{Acknowledgements}

Not applicable.

\section{Funding}

Not applicable - the work was not funded from a grant but it was supported by the Ministry of Science and Higher Education (project no. DS-183 of the Faculty of Physical Education and Sport in Biała Podlaska, Józef Piłsudski University of Physical Education in Warsaw).

\section{Availability of data and materials}

The data used for underlying the conclusions made in this study are stored by Agnieszka Kędra, Jozef Pilsudski University of Physical Education in Warsaw, Branch in Biala Podlaska, Faculty of Physical Education and Sport, Department of Corrective and Compensating Exercises. E-mail: agnieszka.kedra@poczta.fm.

\section{Authors' contributions}

AK preparing concepts, formulating methods, conducting research, interpretation and conclusions, editing the final version. AKG, PK and DC formulating methods, conducting research, interpretation and conclusions, editing the final version. AB formulating methods, statistics, interpretation and conclusions, editing the final version. All authors have read and approved the final manuscript.

\section{Ethics approval and consent to participate}

Prior to the commencement of the study, an approval no. SKE 01-31/2012 from the Ethics Committee of Jozef Pilsudski University of Physical Education in Warsaw was obtained. All the participants signed the written consent to participate in the study.

\section{Consent for publication}

All the participants signed the written consent for publication.

\section{Competing interests}

The authors declare that they have no competing interests.

\section{Publisher's Note}

Springer Nature remains neutral with regard to jurisdictional claims in published maps and institutional affiliations.

\section{Author details}

${ }^{1} J$ ozef Pilsudski University of Physical Education in Warsaw, Faculty of Physical Education and Sport, ul. Akademicka 2, 21-500 Biala Podlaska, Poland. ${ }^{2}$ Jozef Rusiecki University College in Olsztyn, Faculty of Physiotherapy, ul. Bydgoska 33, 10-243 Olsztyn, Poland. ${ }^{3}$ Jozef Pilsudski University of Physical Education in Warsaw, Faculty of Tourism and Sport, ul. Akademicka 2, 21-500 Biala Podlaska, Poland.

Received: 5 July 2017 Accepted: 20 November 2017

Published online: 28 November 2017

\section{References}

1. Meerding WJ, Bonneux L, Polder JJ, Koopmanschap MA, van der Maas PJ. Demographic and epidemiological determinants of healthcare costs in Netherlands: cost of illness study. BMJ. 1998;317(7151):111-5.

2. Ministry of Health Social Affairs. Public health report. Helsinki: Ministry of Health and Social Affairs; 1996.

3. Gatchel RJ, Polatin PB, Noe C, Gardea M, Pulliam C, Thompson J. Treatmentand cost-effectiveness of early intervention for acute low-back pain patients: a one-year prospective study. J Occup Rehabil. 2003;13(1):1-9.

4. Diepenmaat AC, van der Wal MF, de Vet HC, Hirasing RA. Neck/shoulder, low back, and arm pain in relation to computer use, physical activity, stress, and depression among Dutch adolescents. Pediatrics. 2006;117:412-26.

5. Mikkonen P, Leino-Arjas P, Remes J, Zitting P, Taimela S, Karppinen J. Is smoking a risk factor for low back pain in adolescents? A prospective cohort study. Spine. 2008;33:527-32.
6. Kędra A, Czaprowski D. Epidemiology of back pain in children and youth aged 10-19 from the area of the southeast of Poland. Biomed Res Int. 2013; 2013:506823. 10.1155/2013/506823. Epub 2013 Jul 31

7. Poussa MS, Heliövaara MM, Seitsamo JT, Könönen MH, Hurmerinta KA, Nissinen MJ. Predictors of neck pain: a cohort study of children followed up from the age of 11 to 22 years. Eur Spine J. 2005;14:1033-6.

8. Ståhl M, Mikkelsson M, Kautiainen H, Häkkinen A, Ylinen J, Salminen JJ. Neck pain in adolescence. A 4-year follow-up of pain-free preadolescents. Pain. 2004; 110:427-31.

9. Siivola SM, Levoska S, Latvala K, Hoskio E, Vanharanta H, KeinänenKiukaanniemi S. Predictive factors for neck and shoulder pain: a longitudinal study in young adults. Spine. 2004;29:1662-9.

10. Fillingim RB, King CD, Ribeiro-Dasilva MC 3rd, et al. Sex, gender, and pain: a review of recent clinical and experimental findings. J Pain. 2009;10:447-85.

11. Feldman DE, Shrier I, Rossignol M, Abenhaim L. Risk factors for the development of low back pain in adolescence. Am J Epidemiol. 2001;154:30-6.

12. Heneweer $H$, Vanhees L, Picavet HS. Physical activity and low back pain: a U-shaped relation? Pain. 2009;143(1-2):21-5. 10.1016/.jpain.2008.12.033. Epub 2009 Feb 12

13. Brady SR, Hussain SM, Brown WJ, Heritier S, Billah B, Wang Y, Teede H, Urquhart DM, Cicuttini FM. Relationships between weight, physical activity, and back pain in young adult women. Medicine (Baltimore). 2016;95(19): e3368. 10.1097/MD.0000000000003368.

14. Auvinen J, Tammelin T, Taimela S, Zitting P, Karppinen J. Associations of physical activity and inactivity with low back pain in adolescents. Scand J Med Sci Sports. 2008;18:188-94.

15. Abenhaim L, Rossignol M, Valat JP, Nordin M, Avouac B, Blotman F, Charlot J, Dreiser RL, Legrand E, Rozenberg S, Vautravers P. The role of activity in the therapeutic management of back pain. Report of the international Paris task force on back pain. Spine. 2000;25:1S-33S.

16. Hildebrandt VH, Bongers PM, Dul J, van Dijk FJ, Kemper HC. The relations between leisure time, physical activities and musculoskeletal symptoms and disability in worker populations. Int Arch Environ Health. 2000;73:507-18.

17. Jacob T, Baras M, Zeev A, Epstein L. Physical activities and low back pain: a community-based study. Med Sci Sports Exerc. 2004;36:9-15.

18. Sjolie AN. Associations between activities and low back pain in adolescents. Scand J Med Sci Sports. 2004;14:352-9.

19. Balaqué ML, Skovron M, Nordin M, Dutoit G, Waldburger M. LBP In school children: a study of familial and psychological factors. Spine. 1995;20:1265-70

20. Kujala UM, Taimela S, Viljanen T. Leisure physical activity and various pain symptoms among adolesents. Br J Sports Med. 1999;33:323-8.

21. Harreby M, Nygaard B, Jessen T, Larsen E, Storr-Paulsen A. Risk factors for LBP in a cohort of 1389 Danish school children: an epidemiologic study. Eur Spine J. 1999;8:444-50

22. Grimmer K, Williams M. Gender-age environmental associates of adolescent LBP. Appl Ergon. 2000;31:343-60,

23. Brown KW, Cozby PC, Kee DW, Worden PE. Research methods in human development. 2nd ed. Mountain View: Mayfield; 1999. ISBN 1-55934-875-5

24. lacovides S, Avidon I, Bentley A, Baker FC. Reduced quality of life when experiencing menstrual pain in women with primary dysmenorrhea. Acta Obstet Gynecol Scand. 2014;93(2):213-7.

25. McCaffery M, Beebe A. Pain: Clinical Manual for Nursing Practice. St Louis: C V. Mosby Company; 1989.

26. Lewandowski J, Szulc P, Boch-Kmieciak J, Bartkowiak P, Pail O. Epidemiology of low back pain in students of physical education and physiotherapy. Stud Phys Cult Tou. 2011;3:265-9.

27. Taspinar F, Taspinar B, Cavlak U, Celik E. Determining the pain-affecting of university students with nonspecific low back pain. J Phys Ther Sci. 2013; 25(12):1561-4.

28. Kujala UM, Taimela S, Erkintalo M, Salminen JJ, Kaprio J. Low-back pain in adolescent athletes. Med Sci Sports Exerc. 1996;28(2):165-70.

29. Lundin O, Hellström M, Nilsson I, Swärd L. Back pain and radiological changes in the thoraco-lumbar spine of athletes. A long-term follow-up. Scand J Med Sci Sports. 2001;11(2):103-9.

30. Baranto A, Hellström M, Nyman R, Lundin O, Swärd L. Back pain and degenerative abnormalities in the spine of young elite divers: a 5-year follow-up magnetic resonance imaging study. Knee Surg Sports Traumatol Arthrosc. 2006:14(9):907-14. Epub 2006 Jan 17

31. Swärd L, Hellstrom M, Jacobsson B, Pëterson L. Back pain and radiologic changes in the thoraco-lumbar spine of athletes. Spine (Phila Pa 1976). 1990;15(2):124-9. 
32. Harvey J, Tanner S. Low back pain in young athletes. A practical approach Sports Med. 1991;12(6):394-406.

33. Eriksson K, Németh G, Eriksson E. Low back pain in elite cross-country skiers. A retrospective epidemiological study. Scand J Med Sci Sports. 1996;6(1):31-5.

34. Sassmannshausen G, Smith BG. Back pain in the young athlete. Clin Sports Med. 2002;21(1):121-32.

35. Bahr R, Andersen SO, Løken S, Fossan B, Hansen T, Holme I. Low back pain among endurance athletes with and without specific back loading-a crosssectional survey of cross-country skiers, rowers, orienteerers, and nonathletic controls. Spine (Phila Pa 1976). 2004;29(4):449-54.

Submit your next manuscript to BioMed Central and we will help you at every step:

- We accept pre-submission inquiries

- Our selector tool helps you to find the most relevant journal

- We provide round the clock customer support

- Convenient online submission

- Thorough peer review

- Inclusion in PubMed and all major indexing services

- Maximum visibility for your research

Submit your manuscript at www.biomedcentral.com/submit 